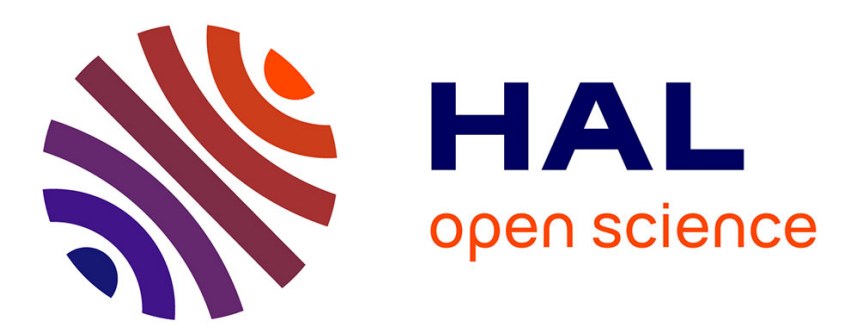

\title{
Spatial relationships between patterned ground and ground ice detected by the Neutron Spectrometer on Mars
}

\author{
N. Mangold, S. Maurice, N. Feldman, F. Costard, F. Forget
}

\section{To cite this version:}

N. Mangold, S. Maurice, N. Feldman, F. Costard, F. Forget. Spatial relationships between patterned ground and ground ice detected by the Neutron Spectrometer on Mars. Journal of Geophysical Research. Planets, 2004, 109 (E8), pp.E8. 10.1029/2004JE002235 . hal-00380066

\section{HAL Id: hal-00380066 https://hal.science/hal-00380066}

Submitted on 10 Feb 2021

HAL is a multi-disciplinary open access archive for the deposit and dissemination of scientific research documents, whether they are published or not. The documents may come from teaching and research institutions in France or abroad, or from public or private research centers.
L'archive ouverte pluridisciplinaire HAL, est destinée au dépôt et à la diffusion de documents scientifiques de niveau recherche, publiés ou non, émanant des établissements d'enseignement et de recherche français ou étrangers, des laboratoires publics ou privés. 


\title{
Spatial relationships between patterned ground and ground ice detected by the Neutron Spectrometer on Mars
}

\author{
N. Mangold, ${ }^{1}$ S. Maurice, ${ }^{2}$ W. C. Feldman, ${ }^{3}$ F. Costard, ${ }^{1}$ and F. Forget ${ }^{4}$ \\ Received 9 January 2004; revised 20 March 2004; accepted 26 May 2004; published 3 August 2004.
}

[1] Patterned grounds, like polygonal features, are the signature of climatic effects in periglacial regions on Earth. Identifying similar features on Mars is important for an understanding of the past Martian climate. In this study we mapped fresh patterned landforms from the systematic analysis of Mars Orbiter Camera high-resolution images. We show that most of them are distributed at latitudes poleward of $\pm 55^{\circ}$, making a climatic control likely. This distribution correlates to the distribution of ground ice detected by the Neutron Spectrometer aboard Mars Odyssey. This correlation is likely the consequence of the Neutron Spectrometer detecting ice no deeper than about $1 \mathrm{~m}$. Patterned ground formation requires ice in this range of depth because these features are triggered by the propagation of a thermal wave that is driven by seasonal or diurnal changes in insolation, which affect the temperature in the uppermost ground layers. Sublimation seems to play a role in the shaping of many of the small patterns observed at latitudes between $55^{\circ}$ and $70^{\circ}$. No widespread polygonal features are correlated to the equatorial regions where hydrogen is detected by the Neutron Spectrometer. INDEX TERMS: 6225 Planetology: Solar System Objects: Mars; 1823 Hydrology: Frozen ground; 1824 Hydrology: Geomorphology (1625); 5470 Planetology: Solid Surface Planets: Surface materials and properties; 5462 Planetology: Solid Surface Planets: Polar regions; KEYWORDS: ground ice, Mars, permafrost

Citation: Mangold, N., S. Maurice, W. C. Feldman, F. Costard, and F. Forget (2004), Spatial relationships between patterned ground and ground ice detected by the Neutron Spectrometer on Mars, J. Geophys. Res., 109, E08001, doi:10.1029/2004JE002235.

\section{Introduction}

[2] The occurrence of polygons on Mars similar to those found on Earth in periglacial regions has been the subject of debate for three decades. Large polygonal systems were identified in Viking images of the Northern plains [Pechmann, 1980; Lucchitta, 1983] as possibly being due to periglacial processes. However, these polygonal features may be better related to tectonic stresses, possibly indicative of a past ocean [Hiesinger and Head, 2000]. New high-resolution images of the Mars Orbiter Camera (MOC) of Mars Global Surveyor (MGS) show small-scale polygons much more similar in size to terrestrial patterned ground [Malin and Edgett, 2000, 2001; Seibert and Kargel, 2001; Yoshikawa, 2002; Mangold et al., 2002; Kuzmin et al., 2002]. If these polygons are caused by periglacial processes, their study can yield information about recent modifications of ice distributions and climate on Mars.

[3] On Earth the formation of patterned ground occurs in periglacial or alpine regions that are subjected to permanent or transient freezing temperatures (Figure 1). Two climatic

\footnotetext{
${ }^{1}$ Orsay-Terre, CNRS et Université Paris-Sud, Orsay, France.

${ }^{2}$ Laboratoire d'Astrophysique, Observatoire Midi-Pyrénées, Toulouse, France.

${ }^{3}$ Los Alamos National Laboratory, Los Alamos, New Mexico, USA.

${ }^{4}$ Laboratoire de Météorologie Dynamique, CNRS, Université Paris VI, Paris, France.
}

Copyright 2004 by the American Geophysical Union. 0148-0227/04/2004JE002235 effects control their formation: (1) freeze-thaw cycles, which form sorted polygons, hummocks, or stripes from ice segregation in lenses and concentration of stones or pebbles [e.g., Goldthwait, 1976; Kessler and Werner, 2003] and (2) thermal contraction, which forms crack networks by volume decrease of the ground ice during winter [e.g., Lachenbruch, 1962; Plug and Werner, 2002]. In these two processes the necessary element is the presence of ice in the ground [e.g., French, 1996]. Our study shows that the global distribution of small-scale polygons on Mars is correlated to the distribution of near-surface ice obtained from the Neutron Spectrometer (NS) aboard Mars Odyssey.

\section{Description and Distribution of Patterned Ground in High-Resolution MOC Images}

[4] A systematic survey of small patterned ground landforms on Mars has been accomplished using MOC images in data sets M01 to E06. These data cover more than one Martian year, so that both hemispheres are equally sampled. Only MOC images having resolution better than $6 \mathrm{~m} /$ pixel that revealed widespread distributions of patterned grounds on a given image (Figure 2a) were included in our study. Images with small patches of patterned grounds were not taken in account because they can be due to local effects. We also avoided old patterns strongly degraded or cratered that may be relics of geologically ancient periods in order to select patterns representative of recent epochs. For example, polygons observed in the NW Elysium and Utopia regions 


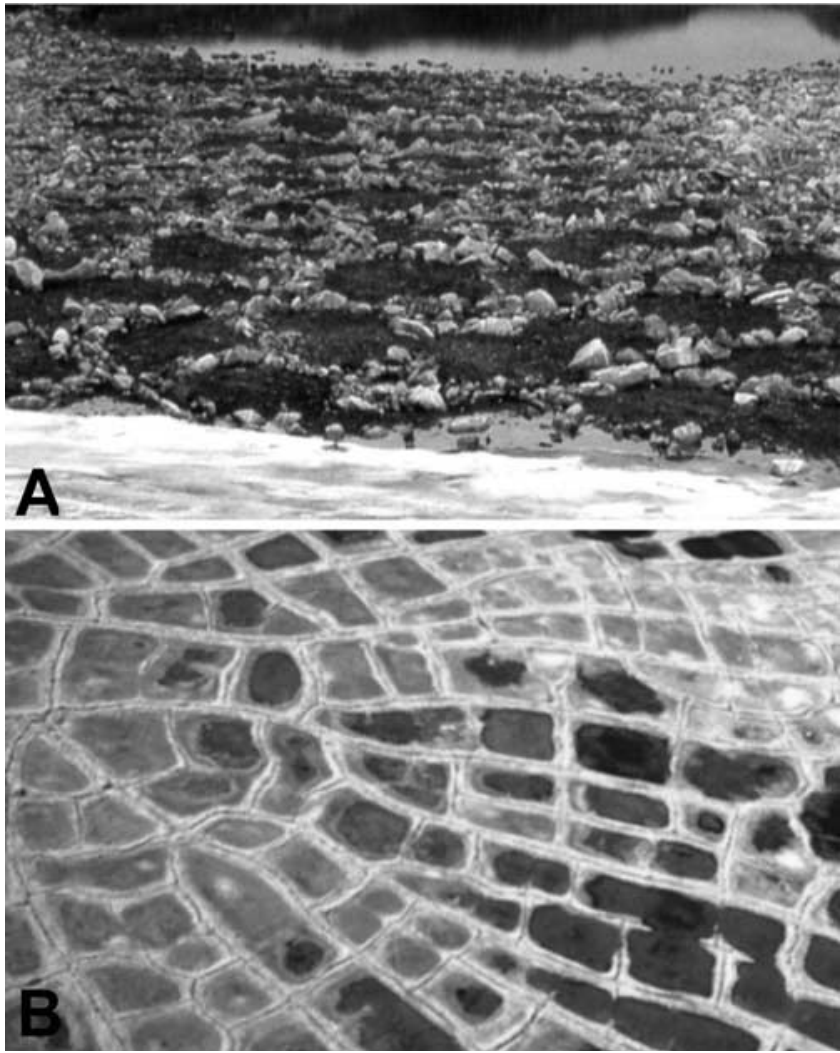

Figure 1. Two types of patterned ground on Earth. (a) $1 \mathrm{~m}$ large sorted polygons formed by freeze-thaw cycles in Jameson Land, Greenland (image J.-P. Peulvast, Orsay). (b) $30 \mathrm{~m}$ large ice wedge polygons formed by cracks due to thermal contraction and seasonal thaw in northern Canada (free document from National Resources Canada (NRC), http://www.rncan.gc.ca).

(around $40^{\circ} \mathrm{N}, 270^{\circ} \mathrm{W}$ ) [Seibert and Kargel, 2001; Kuzmin et al., 2002], as well as those from Athabasca Valles $\left(10^{\circ} \mathrm{N}\right.$, $200^{\circ} \mathrm{W}$ ), were not included for this reason, even though they may have formed during the Late Amazonian period. In fact, only a few images were excluded by these criteria relative to the total of $531 \mathrm{MOC}$ images finally selected. We classed all selected examples into four main categories, as defined by their geometrical characteristics and size (Table 1). It is nevertheless not the goal of this study to propose a detailed classification and interpretation of all types of patterned grounds on Mars.

[5] First, the most frequent type of patterned ground, identified in more than 434 images, consists of very regularly spaced small polygons (hereafter type $S$ ), which are less than $40 \mathrm{~m}$ in diameter (Figures $2 \mathrm{a}$ and $2 \mathrm{~b}$ ). Polygons often form a regular pattern over the whole area of a MOC image and are apparently almost always devoid of sharp edges. Many polygons are outlined by the presence of carbonic ice frost, which suggests bounding troughs separating polygons. Shadows and sun incidence angle also suggest that the centers of these polygons are usually elevated above their borders, but some images may show the inverse geometry. On many images, small polygons consist of a network of hummocks with nearly circular geometry. Such hummocky patterns are similar to what have been named "basketball terrains" [Malin and Edgett, 2001; Head et al., 2003], but it is still unclear if all small polygons of type $\mathrm{S}$ correspond to this nomenclature.

[6] Second, straight boundary troughs define polygons larger than $40 \mathrm{~m}$ (Figures 2c-2e) with geometry similar to terrestrial ice wedge polygons (Figure 1b). They have been divided into three subtypes depending on their homogeneity and distribution. Large homogeneous polygons (type LT and LPC) are 50-300 $\mathrm{m}$ wide (Figure 2c), which is up to five times larger than terrestrial examples. The polygons of type LT (observed in 40 images) are often found in relation to topographic features such as crater floors or hillslopes, as shown in Figure 2c. The other type of large and homogeneous crack networks (type LPC) is found on 19 images located in polar layered deposits around the south polar cap (Figure 2d). A last group of large polygons corresponds to complex and heterogeneous crack networks (type V) with polygons of varying sizes $(20-200 \mathrm{~m})$ as shown in Figure 2e.

[7] Most of these patterns occur in latitudes higher than $55^{\circ}$ in both hemispheres (see Figure 3), making a climatic control in their formation likely. An exception to this rule may be the heterogeneous polygons (V), which are located only in the southern hemisphere, and polygons of type (LPC), which are located only around the south polar cap. Patterned grounds appear equally in Noachian, Hesperian, and Amazonian geological units as established using Viking imagery. The reason is that they are located over young deposits that likely correspond to dusty, loess-like material that contains large amounts of interstitial ice, which mantles the underlying terrain [Tokar et al., 2002; Kreslavsky and Head, 2002], and may also cover layers of pure ice beneath [Mischna et al., 2003]. The relative youthfulness of patterned ground can be estimated by an approximate age deduced from crater counts. Of course, most images are devoid of fresh craters because the young aspect was one of the criteria of the image selection. Nevertheless, assuming that small patterns of type $\mathrm{S}$ are contemporaneous, the crater count of fresh craters superimposed on the patterns over the total surface of images containing small polygons would give an estimate of the crater density for this type of patterned ground. Over 434 images, only 15 fresh small craters between $20 \mathrm{~m}$ and $100 \mathrm{~m}$ in diameter are superimposed over small polygons. Such a low crater density would imply an age of formation strictly lower than $10 \mathrm{Myr}$, and possibly lower than $1 \mathrm{Myr}$, according to most recent timescales [Hartmann and Neukum, 2001]. We are thus looking at very young landforms that could be still in formation.

[8] A first interpretation of the observed features can be proposed given the two main processes of patterned ground formation on the Earth, i.e., thermal contraction and freezethaw cycles. First, thermal contraction at continuously subfreezing temperatures is able to explain the overall geometry of most kinds of large polygons (types LT, LPC, and V) that are bounded by straight troughs. Indeed, seasonal temperature variations should produce cracks in the ground at almost all latitudes poleward of $\pm 20-30^{\circ}$ if ice is present in the ground near enough to the surface [Mellon, 1997]. Nevertheless, on Earth (Figure 1b), seasonal thaw in addition to surface thermal contraction contributes to the formation of a homogeneous geometry of crack networks because of the 

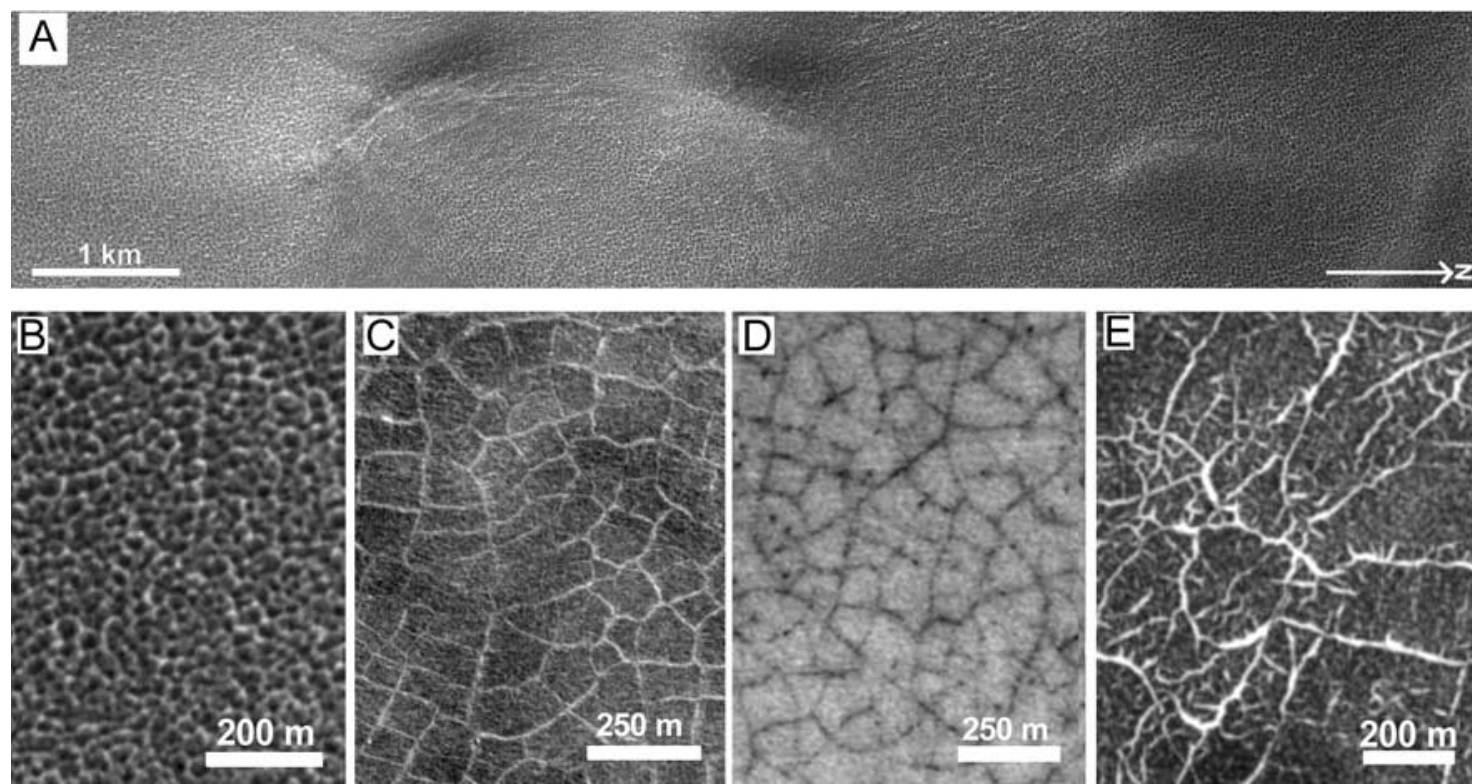

Figure 2. Different examples of high-latitude patterned ground on Mars. (a) Small polygons (type S) observed on the whole length of MOC image M1400154 $\left(60.6^{\circ} \mathrm{N}, 2.9^{\circ} \mathrm{W}\right)$. (b) Close-up over the same MOC image. Polygons are typically $30 \mathrm{~m}$ large. (c) $200 \mathrm{~m}$ wide polygons formed by networks of cracks inside a crater MOC (type LT). MOC image E0300299 $\left(64.7^{\circ} \mathrm{N}, 292.9^{\circ} \mathrm{W}\right)$. (d) Polygons formed by straight cracks around the south polar cap (type LPC). MOC image M0807124 $\left(87.1^{\circ} \mathrm{S}, 315^{\circ} \mathrm{W}\right)$. (e) Networks of cracks forming polygons of heterogeneous size (type V). MOC image M08-05725 $\left(67.7^{\circ} \mathrm{S}, 347.7^{\circ} \mathrm{W}\right)$

formation of ice wedges [e.g., Plug and Werner, 2002]. Alternatively, the sand filling of cracks forming sand wedges can also explain such a homogeneous geometry in the absence of seasonal thaw [e.g., Murton et al., 2000]. At the least, differences in the geometry and distribution of the different types of large polygons suggest that factors other than seasonal temperature variations may be involved in their formation.

[9] Second, given the small size of polygons (type S), the MOC resolution (1.4-6 m per pixel) limits the possibility of comparing their morphology on Mars with terrestrial types of polygons. Their small size may be in agreement with terrestrial sizes of ice wedge polygons, which are typically 20-40 $\mathrm{m}$ in diameter [Lachenbruch, 1962]. However, trough-bounding small polygons of type $\mathrm{S}$ are smooth and devoid of sharp edges, which are different from the straight cracks, indicating that processes other than thermal cracking may be operating. Sorted nets or regular patterns of hummocks formed by periodic seasonal thaw could alternatively explain their formation. The size of $20-40 \mathrm{~m}$ seems nevertheless to be much larger than their terrestrial counterparts, which are usually several meters in diameter [e.g., Kessler and Werner, 2003]. Exceptions to this rule are the $20 \mathrm{~m}$ sorted nets reported by Goldthwait [1976]. Smallscale patterned grounds on Mars thus display different geometries, sizes, and distributions, which may imply different processes of formation, although all examples seem to involve processes that normally occur in polar regions because of variations in temperature and the presence of ground ice.

\section{Geographic Correlation to Subsurface Ice Detected by the Neutron Spectrometer}

[10] Data recently acquired by the Neutron Spectrometer (NS) Mars Odyssey provide a map of the distribution of the

Table 1. Summary of Patterned Ground Type Characteristics

\begin{tabular}{lccccc}
\hline Type $^{\text {a }}$ & Size & $\begin{array}{c}\text { Number } \\
\text { of Images }\end{array}$ & Geometry & Geographical Distribution & Local Characteristics \\
\hline $\mathrm{S}$ & $<40 \mathrm{~m}$ & 434 & $\begin{array}{c}\text { bounding troughs } \\
\text { few apparent cracks) } \\
\text { homogeneous crack }\end{array}$ & high latitude N and S & on all terrain types \\
LT & $>40 \mathrm{~m}$ & 40 & $\begin{array}{c}\text { hetwork } \\
\text { homogeneous crack } \\
\text { network }\end{array}$ & aritude N and S & relations with topography \\
LPC & $>40 \mathrm{~m}$ & 19 & heap & polar layers \\
V & various & 38 & $\begin{array}{c}\text { heterogeneus crack } \\
\text { network }\end{array}$ & S high latitudes & on all terrain types \\
\hline
\end{tabular}

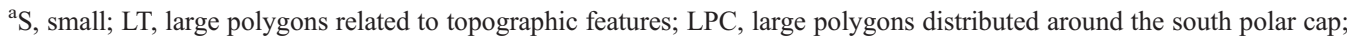
$\mathrm{V}$, polygons of various size. 


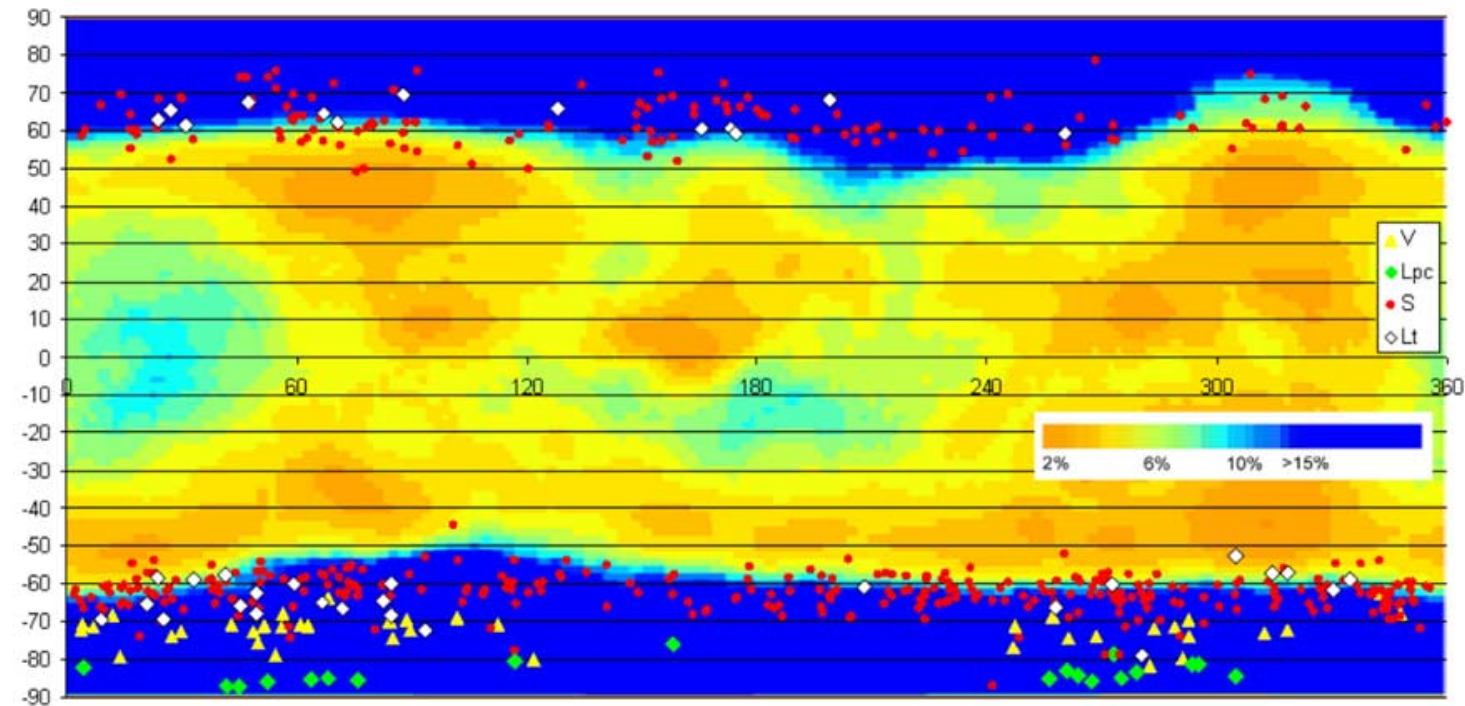

Figure 3. Distribution of polygons on Mars: V, large heterogeneous polygons; LPC, straight crack networks close to south polar cap; LT, large homogeneous polygons formed by cracks associated with topography; S, homogeneous polygons of size smaller than $40 \mathrm{~m}$. The color map corresponds to ground ice proportion in mass as measured by the Neutron Spectrometer (see text for explanation).

Martian water-equivalent hydrogen in the near-subsurface [Feldman et al., 2002, 2003]. Such a data set can be immediately compared to our distribution of polygonal features. First, we shall review how the water distribution was derived and what its limitations are.

[11] The sensor element of the NS allows measurements of upward currents of epithermal $(0.4 \mathrm{eV}<$ energy $<$ $0.7 \mathrm{MeV}$ ) neutrons. The data have been recently calibrated in an absolute manner, using counting rates measured when the spacecraft was poleward of $\pm 85^{\circ}$ latitude, when the northern and southern $\mathrm{CO}_{2}$ caps were near maximum [Feldman et al., 2003; Prettyman et al., 2004]. $\mathrm{A} \mathrm{CO}_{2}$ frostfree map of epithermal neutron counting rates was constructed, using data measured before the autumnal equinox in the south (corresponding to solar longitudes, $\mathrm{L}_{\mathrm{s}}$, between $-30^{\circ}$ and $0^{\circ}$ ) and data measured after $\mathrm{L}_{\mathrm{s}}=100^{\circ}$ in the north. Data within the middle band of latitudes were averaged over the entire data set. Uncertainties in epithermal neutron counting rates are estimated to be less than about $\pm 10 \%$. The surface resolution of such a map is $\sim 600 \mathrm{~km}$, the full width at half maximum of the spatial footprint of the NS. Finally, the depth sampled from orbit is simulated to be $<1 \mathrm{~m}$.

[12] The connection between measured neutron counting rates and water-equivalent hydrogen was made by combining epithermal counting-rate data with a simulated model of the instrument response function. This step relies on a simple two-layer model of the stratigraphy of the ground. For this study we shall use abundances derived for a semi-infinite soil layer whose composition is that of Pathfinder mixed with an assumed water concentration. Other possibilities, which include a desiccated layer at the surface, for instance, are nevertheless likely [Mellon and Jakosky, 1995]. The advantage of a semi-infinite soil layer is that it provides a lowerlimit abundance of water-equivalent hydrogen [Feldman et $a l ., 2002]$. When all uncertainties are folded together, the estimates of $\mathrm{H}_{2} \mathrm{O}$ mass fractions are accurate to less than about $\pm 15 \%$ of the estimated mass fraction [Feldman et al.,
2004; Prettyman et al., 2004]. We note that neutron spectroscopy is sensitive only to the abundance of hydrogen, regardless of its molecular associations, although it has been quantified in terms of water-equivalent hydrogen mass fraction by the Odyssey team. Hydrogen-rich deposits could indeed contain hydrated minerals, since they may sequester water as structural $\mathrm{H}_{2} \mathrm{O}$ and $\mathrm{OH}$ in amounts of $\sim 10-20 \%$ [Bish et al., 2003]. Therefore the role of hydrous minerals could be significant at equatorial latitudes, but it must be dominated by deposits of water ice poleward $\pm 60^{\circ}$, where concentrations are well above $20 \%$ by mass.

[13] Figure 3 provides lower limits of the $\mathrm{H}_{2} \mathrm{O}$ abundances in the major $\mathrm{H}_{2} \mathrm{O}$-bearing layers within the uppermost meter of Mars. Inspection shows that hydrogen-rich deposits ranging between $20 \%$ and $100 \%$ water-equivalent by mass are found poleward of $\pm 55^{\circ}$ latitude and less rich, but significant deposits are found at near-equatorial latitudes. The lower boundary of small patterns (type S) and large polygons (type LT) follows the boundary of ground ice having mass percents greater than $15-20 \%$ at $\pm 55^{\circ}-60^{\circ}$ latitude. This coincidence suggests a direct relationship between the landforms and the presence of the ground ice.

[14] On Earth, processes like thermal contraction and freeze-thaw cycles affect only the top few meters of the ground because they are caused by the propagation of seasonal or diurnal thermal waves. Although seasonal thaw is not currently possible on Mars, recent periods of relatively high obliquity may have permitted above freezing temperatures even on flat surfaces [Costard et al., 2002, Figure 3b]. Regardless, daily temperature changes during the present obliquity cycle may also produce polygonal features. Whereas the maximum propagation depth of the diurnal thermal wave is currently limited to the top $10 \mathrm{~cm}$ [Mellon, 1997], seasonal temperature variations can induce cracking down to a maximum of 2 or $3 \mathrm{~m}$, depending on the thermal properties of the ground [Mellon, 1997]. These estimated depths take into account the temperature varia- 
tions induced by the seasonal deposition of $\mathrm{CO}_{2}$ ice every winter, which occurs poleward of about $55^{\circ}$. These depths are comparable to the maximum detection depth of large deposits of hydrogen detected by NS of about $1 \mathrm{~m}$. Ground ice may exist deeper than $1 \mathrm{~m}$ in regions of $40^{\circ}-50^{\circ}$ of latitude without being detected by GRS data [e.g., Boynton and the GRS Team, 2002], but polygons cannot exist at these depths because the seasonal thermal wave should not reach the ground ice. The probable cause of the correlation between the ground ice detected using NS and the patterned ground observed using MOC is that the processes that form polygons such as thermal contraction, or freeze-thaw cycles if existing, occur only if water ice is present in the uppermost meter of the ground.

\section{Discussion}

[15] The relationship between ground ice detected by NS and patterns observed in MOC images is much closer in the southern hemisphere than in the northern hemisphere. On the NW of the Tharsis volcanoes the Neutron Spectrometer detects near-surface ice down to $50^{\circ}$ of latitude, whereas polygons seem to exist only north of $55^{\circ}$ latitude. By contrast, polygons are found in the latitudes $50^{\circ}-60^{\circ} \mathrm{N}$ at longitudes of $80^{\circ}-100^{\circ} \mathrm{E}$ and $290^{\circ}-320^{\circ} \mathrm{E}$, whereas the neutron data indicate a limit of ground ice around $60^{\circ}$ and $70^{\circ}$, respectively. Some of the regional differences could be due to local variations in the propagation of the thermal wave in the ground caused by differences in soil composition or the thermophysical properties of the soil [Mellon, 1997]. We note, however, that substantial deposits of water ice may exist below about $1 \mathrm{~m}$ without being detected by NS. Regional variations in the $\pm 55^{\circ}-60^{\circ}$ latitude may also come from the relative age of features, which may have formed in periods when ice was stable at the same depth at more equatorward latitudes due to relatively high obliquities in the recent past [Mischna et al., 2003].

[16] At the difference of large polygons, small patterned grounds (S) are not observed in regions poleward of $75^{\circ}$ despite the fact that ground ice is present close to the surface. We suggest hereafter that this characteristic may be an effect of degradation of these patterns by desiccation. Indeed, the current atmospheric conditions imply that the ground at latitudes of $60^{\circ}-70^{\circ}$ is subjected to progressive desiccation in the topmost centimeters [Mellon and Jakosky, 1995]. This model assumes that the ground is a continuous medium. If the ground is fractured, and contains cracks formed by thermal contraction, these fractures permit a more rapid sublimation of ice as shown for fractures over glacier like landforms [Mangold, 2003a, Figure 6]. Indeed, ice grains in the fracture sublime quickly because they are directly in contact with the atmosphere. Solid grains then fall down in the trough, and the next ice grains are quickly in contact with the atmosphere. Initial cracks would thus become wider and wider because of their progressive erosion and degradation. This situation is different from homogeneous layers where the porosity of the ice-free overburden decreases the sublimation rate of interstitial ice of the underlying layers. Such a process is seemingly observed in subglacial till in Antarctica [Marchant et al., 2002; Head et al., 2003; Sletten et al., 2003], where pure ice layers exist underneath rocks. This view is thus mainly consistent with the explanation of "basketball terrains" given by Head et al. [2003]. Similar widening of troughs can also exist because of the melting of the ground ice, which produces collapse of the wedge [French, 1996, Figure 7.7], but on Mars, thermal contraction and desiccation at constantly subfreezing temperatures are likely sufficient to produce such geometry.

[17] The described process may explain the shape of most small polygons (type $S$ ) by (1) the formation of cracks by thermal contraction and (2) the subsequent widening of cracks by desiccation and erosion of the loose material filling the trough. If the foregoing process obtains, desiccation should not be very efficient at latitudes close to the pole [Mellon and Jakosky, 1995], where fresh cracks would not be widened by sublimation. The pixel size of MOC images is typically $2.8 \mathrm{~m}$, implying that only troughs larger than this value are visible. Therefore small cracks not widened by thermal contraction could exist poleward of $75^{\circ}$ yet not be visible in MOC images, thereby explaining their apparent absence in the most poleward regions. On the other hand, pure desiccation without thermal contraction cracks would not explain the regular geometry of small patterned ground (S), which is different from the irregularly dissected terrains observed in the $30^{\circ}-55^{\circ}$ latitude zones by Mustard et al. [2001]. Small patterned ground could thus make the transition between the strongly desiccated terrains observed by Mustard et al. [2001] and the less desiccated terrains poleward of $70^{\circ}-75^{\circ}$ of latitude.

[18] Large polygons clearly bounded by straight cracks have sizes larger than small patterns bounded by troughs resulting from possible degraded cracks. If small patterns (type S) are formed by thermal contraction, one would ask why large networks (types LT and LPC) are five times larger than small patterns $(S)$ if they are caused by the same seasonal contraction. The answers may be found either in the age of the features (because large polygons could correspond to older features formed under different climatic conditions) or in the periodicity of the thermal variations (because diurnal, annual, or longer cycles would form features of different sizes). Among all examples of observed patterned ground, some could also be due to seasonal thaw rather than thermal contraction like slope stripes and some ice wedge-like polygons [Mangold, 2003b]. The fact that their distribution is also consistent with the distribution of ground ice shows that they are recent features, even possibly tens of thousands of years old. However, questions of the climatic control of those patterns that involve past obliquity variations are out of the scope of this study.

[19] Finally, the Neutron Spectrometer data show an amount of hydrogen equivalent to as much as $10 \%$ of ice by mass in equatorial regions of Arabia Terra and southwest Tharsis. This unexpected observation could reveal the presence of ground ice buried beneath a dry layer, which provides a poor vapor connection to the surface [Feldman et al., 2004]. No widespread patterned ground is found to be correlated to these potential patches of equatorial ground ice. According to Mellon [1997], regions poleward of $20^{\circ}$ to $30^{\circ}$ are likely to display thermal contraction if ground ice is present in the uppermost meter of the surface. The presence of ground ice should create cracks, which would lead to the formation of patterned ground. The lack of patterned ground in these regions leads us to conclude either that the thermal 
properties of the uppermost layers in these regions are different from those assumed by present models or that the hydrogen detected by NS is in the form of hydrated minerals rather than water ice.

\section{Conclusion}

[20] More than 500 MOC images of the high-latitude regions of Mars show the presence of small-scale polygons from 20 to $300 \mathrm{~m}$ in diameter. The distribution of most polygons at similar latitudes in both hemispheres is clear evidence for climatic control. The distribution in latitude of these polygons shows a strong correlation to the onset of ground ice detected by the Mars Odyssey Neutron Spectrometer poleward of about $\pm 55^{\circ}$. This correlation can be explained because (1) these features are geologically recent and thus still associated with the current near-surface ground ice distribution and (2) these features are formed by cyclic variations of surface temperatures, thereby requiring ground ice in the uppermost meter of the ground for their genesis. This depth corresponds to the maximum depth of detection of water ice by the Neutron Spectrometer. Progressive desiccation of the top layer may explain the shape of most polygons and hummocks smaller than $40 \mathrm{~m}$ by the progressive widening of the cracks formed by thermal contraction. No patterned ground is observed to be associated with the potential ice-rich areas of the equatorial regions.

[21] Acknowledgments. The authors are grateful to Mike Mellon and George McGill for helpful reviews. The authors acknowledge the use of Mars Orbiter Camera images processed by Malin Space Science Systems that are available at http://www.msss.com/moc_gallery/ and at the USGS at http://ida.wr.usgs.gov/. This work has been granted by the PNP (Programme National de Planétologie) of INSU (Institut National des Sciences de l'Univers) of France.

\section{References}

Bish, D. L., D. T. Vaniman, C. Fialips, J. W. Carey, W. C. Feldman (2003), Can hydrous minerals account for the observed mid-latitude water on Mars?, paper presented at 6th International Conference on Mars, Lunar and Planet. Inst., Houston, Tex.

Boynton, W. V., and the GRS Team (2002), Distribution of hydrogen in the near-surface of Mars: Evidence for subsurface ice deposits, Science, 297, $71-75$.

Costard, F., F. Forget, N. Mangold, and J.-P. Peulvast (2002), Formation of recent Martian debris flows by melting of near-surface ground ice at high obliquity, Science, 295, 110-113.

Feldman, W. C., et al. (2002), Global distribution of neutrons from Mars: Results from Mars Odyssey, Science, 297, 75-78.

Feldman, W. C., et al. (2003), $\mathrm{CO}_{2}$ frost cap thickness on Mars during northern winter and spring, J. Geophys. Res., 108(E9), 5103, doi:10.1029/ 2003JE002101.

Feldman, W. C., et al. (2004), The global distribution of near-surface hydrogen on Mars, J. Geophys. Res., 109, doi:10.1029/2003JE002160, in press.

French, H. M. (1996), The Periglacial Environment, 2nd ed., AddisonWesley-Longman, Reading, Mass.

Goldthwait, R. P. (1976), Frost sorted patterned ground, Quat. Res., 6, $27-35$.

Hartmann, W. K., and G. Neukum (2001), Cratering chronology and evolution of Mars, Space Sci. Rev., 96(1-4), 165-194.

Head, J. W., J. F. Mustard, M. A. Kreslavsky, R. E. Milliken, and D. R. Marchant (2003), Recent ice ages on Mars, Nature, 426, 797-802.

Hiesinger, H., and J. W. Head (2000), Characteristics and origin of polygonal terrain in southern Utopia Planitia, Mars, J. Geophys. Res., 105(E5), 11,999-12,022.

Kessler, M. A., and B. T. Werner (2003), Self-organization of sorted patterned ground, Science, 299, 380-382.

Kreslavsky, M. A., and J. W. Head (2002), Mars: Nature and evolution of young latitude-dependent water-ice-rich mantle, Geophys. Res. Lett., 29(15), 1719, doi:10.1029/2002GL015392.
Kuzmin, R. O., E. D. Ershow, I. A. Komarow, A. H. Kozlov, and V. S. Isaev (2002), The comparative morphometric analysis of polygonal terrain on Mars and the Earth high latitude areas, Proc. Lunar Planet. Sci. Conf. $33 r d$, abstract 2030.

Lachenbruch, A. (1962), Mechanics of thermal contraction cracks and icewedge polygons in permafrost, Spec. Pap. Geol. Soc. Am., 70, 69.

Lucchitta, B. K. (1983), Permafrost on Mars: Polygonally fractured ground, in Permafrost: 4th International Conference Proceedings, pp. 744-749, Natl. Acad. Press, Washington, D. C.

Malin, M. C., and K. S. Edgett (2000), Evidence for recent groundwater seepage and surface run-off on Mars, Science, 288, 2330-2335.

Malin, M. C., and K. S. Edgett (2001), Mars Global Surveyor Mars Orbiter Camera: Interplanetary cruise through primary mission, J. Geophys. Res., 106(E10), 23,429-23,570.

Mangold, N. (2003a), Geomorphic analysis of lobate debris aprons on Mars at Mars Orbiter Camera scale: Evidence for ice sublimation initiated by fractures, J. Geophys. Res., 108(E4), 8021, doi:10.1029/2002JE001885.

Mangold, N. (2003b), Patterned ground on Mars: Evidence for recent freeze-thaw cycles in high latitudes, paper presented at 8th International Permafrost Conference, Int. Permafrost Assoc., Zurich.

Mangold, N., F. Forget, F. Costard, and J.-P. Peulvast (2002), High latitude patterned grounds on Mars: Evidence for recent melting of near-surface ground ice, Proc. Lunar Planet. Sci. Conf. 33rd, abstract 1912.

Marchant, D. R., A. Lewis, W. C. Phillips, E. J. Moore, R. A. Souchez, G. H. Denton, D. E. Sugden, N. Potter Jr., and G. P. Landis (2002), Formation of patterned-ground and sublimation till over Miocene glacier ice in Beacon Valley, Antarctica, Geol. Soc. Am. Bull., 114(6), 718-730.

Mellon, M. T. (1997), Small-scale polygonal features on Mars: Seasonal thermal contraction cracks in permafrost, J. Geophys. Res., 102(E11), $25,617-25,628$.

Mellon, M. T., and B. M. Jakosky (1995), The distribution and behavior of Martian ground ice during past and present epochs, J. Geophys. Res., 100, 11,781-11,789.

Mischna, M. A., M. I. Richardson, R. J. Wilson, and D. J. McCleese (2003), On the orbital forcing of Martian water and $\mathrm{CO}_{2}$ cycles: A general circulation model study with simplified volatile schemes, J. Geophys. Res., 108(E6), 5062, doi:10.1029/2003JE002051.

Murton, J. B., P. Worsley, and J. Gozdzik (2000), Sand veins and wedges in cold aeolian environments, Quat. Sci. Rev., 19, 899-922.

Mustard, J. F., C. D. Cooper, and M. K. Rifkin (2001), Evidence for recent climate change on Mars from the identification of youthful near-surface ground ice, Nature, 412, 411-413.

Pechmann, J. C. (1980), The origin of polygonal troughs on the Martian northern plains, Icarus, 42, 185-210

Plug, L. J., and B. T. Werner (2002), Nonlinear dynamics of ice-wedge networks and resulting sensitivity to severe cooling events, Nature, 417, 929-932.

Prettyman, T. H., et al. (2004), Composition and structure of the Martian surface at high southern latitudes from neutron spectroscopy, J. Geophys. Res., 109, E05001, doi:10.1029/2003JE002139.

Seibert, N. M., and J. S. Kargel (2001), Small-scale Martian polygonal terrain: Implications for liquid surface water, Geophys. Res. Lett., 28(5), 899-902.

Sletten, R. S., B. Hallet, and R. C. Fletcher (2003), Resurfacing time of terrestrial surfaces by the formation and maturation of polygonal patterned ground, J. Geophys. Res., 108(E4), 8044, doi:10.1029/ 2002JE001914

Tokar, R. L., W. C. Feldman, T. H. Prettyman, K. R. Moore, D. J. Lawrence, R. C. Elphic, M. A. Kreslavsky, J. W. Head III, J. F. Mustard, and W. V. Boynton (2002), Ice concentration and distribution near the south pole of Mars: Synthesis of Odyssey and Global Surveyor analyses, Geophys. Res. Lett., 29(19), 1904, doi:10.1029/ 2002GL015691.

Yoshikawa, K. (2002), Origin of the polygons and underground structures in Western Utopia Planitia on Mars, Proc. Lunar Planet. Sci. Conf. 33rd, abstract 1159 .

F. Costard and N. Mangold, Orsay-Terre, FRE2566, CNRS and Université Paris-Sud, Bat. 509, 91405 Orsay Cedex, France. (fcostard@ geol.u-psud.fr; mangold@geol.u-psud.fr)

W. C. Feldman, Los Alamos National Laboratory, MS D-466, Los Alamos, NM 87545, USA. (wfeldman@lanl.gov)

F. Forget, Laboratoire de Météorologie Dynamique, CNRS, Université Paris VI, BP 99,4 place Jussieu, 75252 Paris Cedex 05, France. (francois.forget@lmd.jussieu.fr)

S. Maurice, Laboratoire d'Astrophysique, Observatoire Midi-Pyrénées, 9 avenue du Colonel Roche, F31400 Toulouse, France. (sylvestre.maurice@ cesr.fr) 